\title{
Experimental Study on the Progressive Collapse Resistance of RC Slabs
}

\author{
Peiqi Ren ${ }^{1}$, Yi Li ${ }^{2}$, Yulong Zhou ${ }^{3}$, Xinzheng $\mathrm{Lu}^{4}$, Hong Guan ${ }^{5}$ \\ 1 Key Laboratory of Civil Engineering Safety and Durability of Ministry of \\ Education, Tsinghua University, Beijing, 100084, China. \\ 2 Key Laboratory of Urban Security and Disaster Engineering of Ministry of \\ Education, Beijing University of Technology, Beijing, 100124, China. \\ ${ }^{3}$ School of Civil Engineering, Yantai University, Yantai, 264005, China. \\ 4 Key Laboratory of Civil Engineering Safety and Durability of Ministry of \\ Education, Tsinghua University, Beijing, 100084, China. (Corresponding author). \\ Email: luxz@tsinghua.edu.cn. \\ 5 Griffith School of Engineering, Griffith University Gold Coast Campus, \\ Queensland 4222, Australia.
}

\begin{abstract}
To study the influence of slabs on the progressive collapse resistance of reinforced concrete (RC) frame structures, two 1:3 scaled substructures S1 (with slab) and B1 (without slab) were comprehensively tested. Both specimens had two spans, and each span had a length of $2 \mathrm{~m}$. The width of the floor slab for $\mathrm{S} 1$ is $1 \mathrm{~m}$ for each side of the centerline frame beam. The two opposite sides of the specimens were completely fixed, and the remaining opposite sides were free. Two hydraulic jacks were applied at the top and bottom of the middle beam-column joint. At the beginning of the experiment, these two hydraulic jacks applied a pair of small balanced forces synchronously. Next, the bottom jack maintained the constant force, and at the same time, gradually increased the force of the top jack. Displacement controlled loading was used to simulate the failure of the middle column. By analyzing the load carrying capacities of S1 and B1, the influence of the slab on the progressive collapse resistance of the RC frame structures was discussed.
\end{abstract}

Key words: progressive collapse, concrete structure, experimental test, slab, frame beam.

\section{INTRODUCTION}

The progressive collapse of building structures under accidental loads (e.g., gas explosion, bomb attack, vehicle crash) has been a widely held concern in civil engineering. In recent years, several important or landmark buildings have been built around the world. The progressive collapse of large public buildings due to accidental loads may cause a massive loss of life and property. Hence, the conventional bearing capacity design and seismic design as well as the progressive 
collapse prevention design against accidental loads should be considered for these buildings.

The research on the progressive collapse of reinforced concrete (RC) structures, which is a major form of building structures, has made substantial progress in recent years. Many experimental and numerical investigations have been conducted to explore the progressive collapse performance of $\mathrm{RC}$ structures. The numerical simulation method is very suitable for establishing a three-dimensional model of the whole structural system and for analyzing its mechanical behavior during the entire collapse process ( $\mathrm{Fu}$ 2009, Kwasniewski 2010, Sagiroglu and Sasani 2013). On the other hand, the experimental study can truly demonstrate the local damage of components under large deformation and extract the effect of the deformation on the collapse resistance of structures. Recent experimental studies of RC structures mainly focus on components or substructures, such as planner frame structures (Yi et al. 2008) and beam-column substructures (Su et al. 2009, Kai and Li 2011, Sadek et al. 2011, Kai and Li 2012a).

Floor slabs are one of the main components that provide collapse resistance in RC frame systems. However, limited experimental research has been conducted for investigating the progressive collapse resistance of RC slabs. Kai and Li (2012b) have tested the RC substructure after the loss of a corner column. In their test, slab effects on the collapse resistance were discussed by comparing the results of the specimens with and without a slab. The experimental results showed that the slab could significantly improve the progressive collapse resistance of the substructure via the tensile membrane effects exist in the slab under a large deformation state which was also confirmed by the other tests (Foster et al. 2004, Gouverneur et al. 2013). In the study of the progressive collapse prevention design of RC frames ( $\mathrm{Li}$ et al. 2011), the catenary action through the RC frame beams in the internal region of the structure contributes more collapse resistance than in the corner region. But the corresponding tensile membrane effects of the slabs to the progressive collapse resistance of the RC frame has not been investigated. Thus, in this paper, the internal region of the floor system was experimentally studied to examine the effect of slabs on the progressive collapse resistance of RC frames. Two specimens, S1 (with slab) and B1 (without slab), were comparatively tested following the failure of the internal middle column and the collapse mechanism of the two specimens was discussed.

\section{EXPERIMENTAL SUBSTRUCTURES}

The prototype structure is a 6-story $\mathrm{RC}$ frame structure, which is designed according to the Chinese design codes (i.e., the Code for design of concrete structures GB50010-2010 (MOHURD 2010a) and the Code for Seismic Design of Buildings GB50011-2010 (MOHURD 2010b)). The structure in both the X-and Y-direction is $6 \mathrm{~m}, 4$ spans in total (Figure 1). The story height of the first floor is $4.2 \mathrm{~m}$, and the 
story height of the remaining floors (the second to the sixth floors) is $3.6 \mathrm{~m}$. The seismic design intensity is 7 degrees (the peak ground acceleration for a $10 \%$ exceedance probability in 50 years is $0.10 \mathrm{~g}$, where $\mathrm{g}$ is the acceleration of gravity), and the seismic design group is Group I . The site class of the prototype structure is class II (soil shear wave velocity $500 \mathrm{~m} / \mathrm{s} \geq v_{\mathrm{s}} \geq 250 \mathrm{~m} / \mathrm{s}$ ). The middle two spans in the $\mathrm{X}$-direction and the $1 / 2$ span in the Y-direction from the first story of the prototype structure (see the red rectangle dashed line in Figure 1) are selected as the test substructure. In this test, the reduced scale of specimens is $1 / 3$, which is the same as the existing studies (Yi et al. 2008, Kai and Li (2012a, 2012b)). This reduced scale is chosen due to the limitation of the test site and the size effect on the scaled specimens to accurately represent the mechanical behavior of the prototype structure. The planner view of the reduced specimen S1 is shown in Figure 2. The support beams provide effective boundary constraints for the specimen, and the two hoisting beams are integrated with the specimen to avoid potential damage to the specimen during the hoisting procedure. A concrete stub in the middle of the specimen represents the failed middle column. Based on S1, the slab is removed in specimen B1 to represent the RC frame without a slab. Figure 3 shows the specimens S1 and $\mathrm{B} 1$ at the beginning of the test.

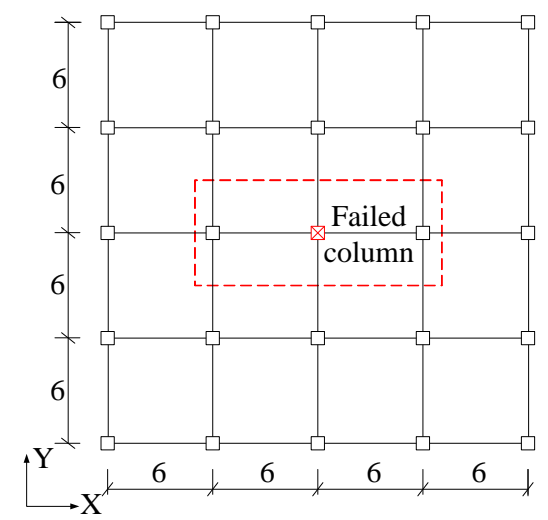

Figure 1. Plan view of the prototype structure (unit: m)

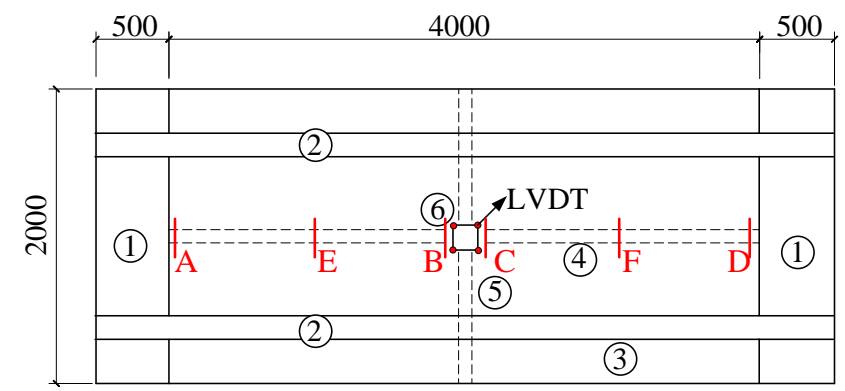

1 Support beam 2 Hoisting beam 3 Slab 4 X-beam 5 Y-beam 6 Concrete stub

Figure 2. Plan view of specimen S1 (unit: $\mathbf{m m}$ ) 


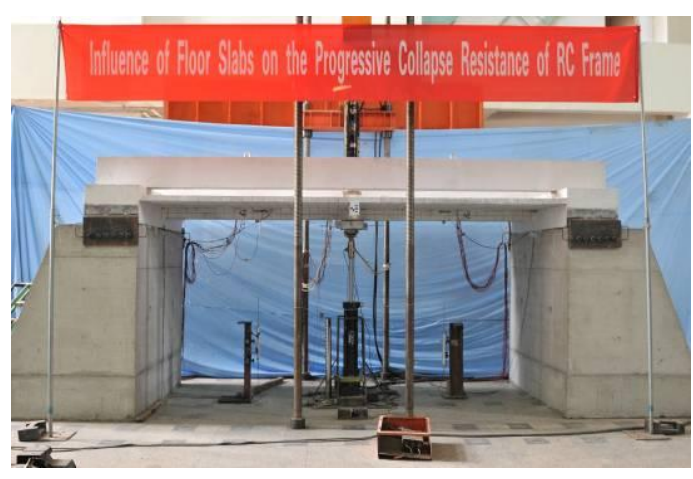

(a) Slab specimen S1 (including beam)

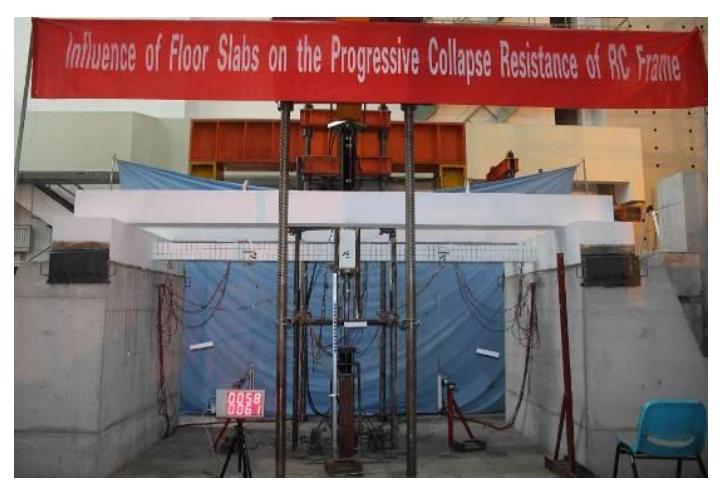

(b) Beam specimen B1

Figure 3. Overview of the specimens at the start of the test

For specimen S1, the X-beam and Y-beam have identical sectional sizes: $85 \mathrm{~mm}$ $\times 170 \mathrm{~mm}$. The thickness of the slab is $50 \mathrm{~mm}$. The concrete cover of the beam and the slab are $6 \mathrm{~mm}$ and $5 \mathrm{~mm}$, respectively. The reinforcement ratio of the specimen is the same as the prototype structure (see Table 1). The reinforcement details of S1 are shown in Figure 4. Compared with S1, the slab (including the slab reinforcement) is removed in $\mathrm{B} 1$, but the remaining parameters are kept the same. The average concrete compressive stress (28-day compressive strength of the cube concrete with the side length equal to $150 \mathrm{~mm}$ ) for $\mathrm{S} 1$ and $\mathrm{B} 1$ are $42.25 \mathrm{MPa}$ and $36.86 \mathrm{MPa}$, respectively. The yield strength of the reinforcements $\phi 6$ and $\phi 8$ used in S1 and B1 are $425 \mathrm{MPa}$ and $370 \mathrm{MPa}$, respectively, and the ultimate tensile strength of the reinforcements are $570 \mathrm{MPa}$ and $470 \mathrm{MPa}$, respectively.

Table 1. Reinforcement ratio of the specimen

\begin{tabular}{c|c|c|c|c|c}
\hline \multicolumn{2}{c|}{ Section 1-1 } & \multicolumn{2}{c|}{ Section 2-2 } & \multicolumn{2}{c}{ Slab* } \\
\hline Beam top & Beam bottom & Beam top & Beam bottom & Slab top & Slab bottom \\
\hline $0.89 \%$ & $0.70 \%$ & $0.70 \%$ & $0.70 \%$ & $0.30 \%$ & $0.30 \%$ \\
\hline
\end{tabular}

Note: ${ }^{*}$ The reinforcement ratio in both the $\mathrm{X}$ - and $\mathrm{Y}$ - directions are the same (equal to $0.30 \%$ ).

${ }^{* *}$ Negative moment area in the prototype structure.

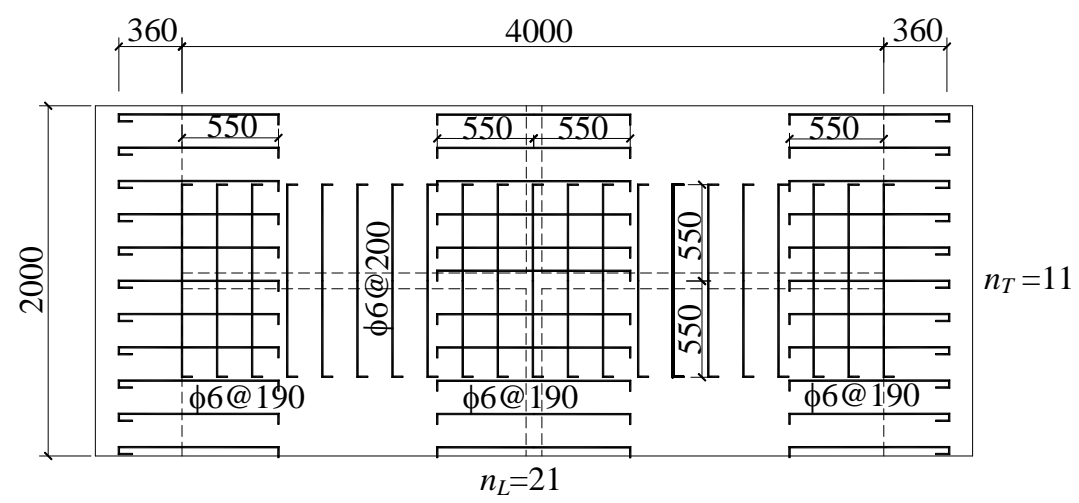

(a) Top reinforcement in the slab 


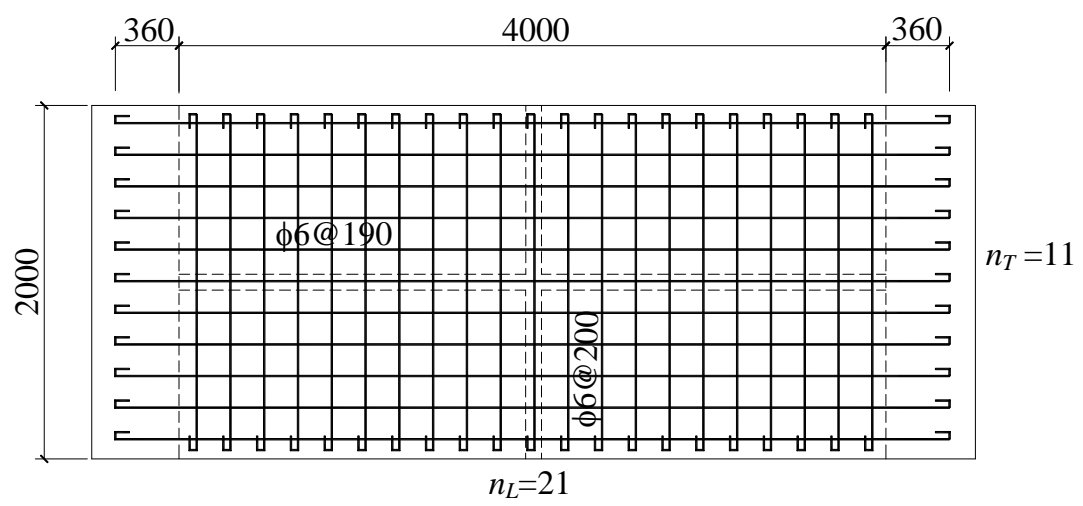

(b) Bottom reinforcement in the slab

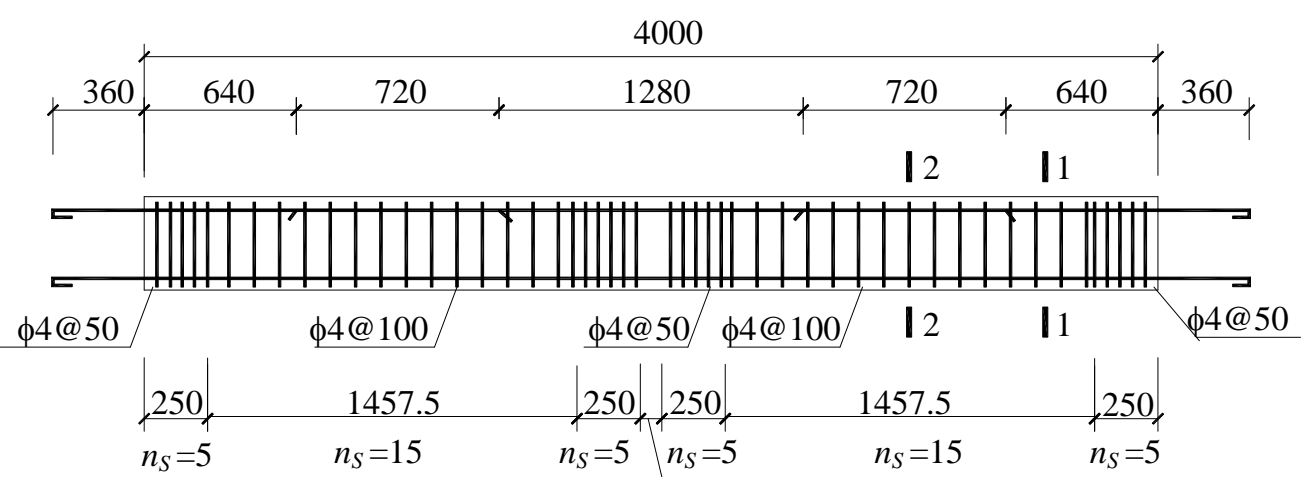

85

(c) Reinforcement in the X-beam

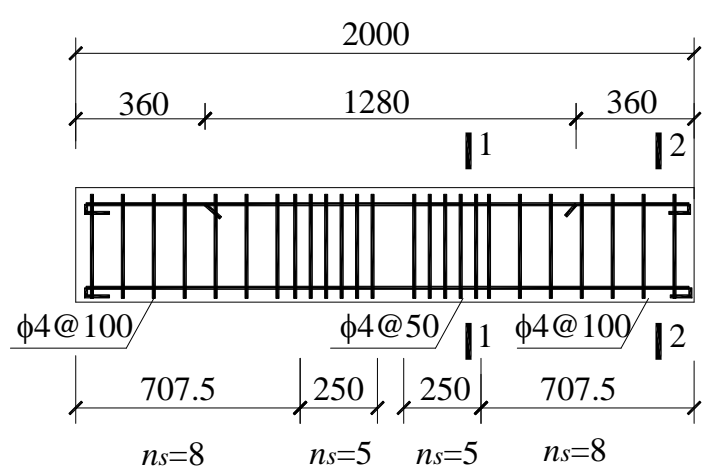

(d) Reinforcement in the Y-beam

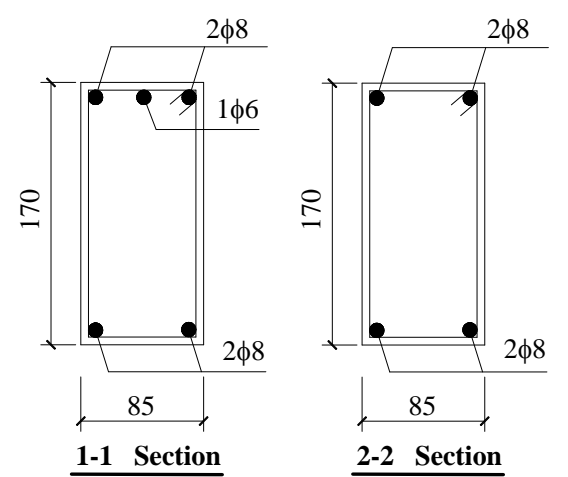

(e) Sectional view of the beam

\section{Figure 4. Detail of the reinforcement in S1}

Note:

(1) $n_{T}$ : number of the steel bars in the Y-direction; $n_{L}$ : number of the steel bars in the X-direction

(2) $n_{S}$ : number of the stirrups

(3) $\$ 6 @ 190$ represents that the diameters of the steel bars are $6 \mathrm{~mm}$ and their spaces are $190 \mathrm{~mm}$.

\section{EXPERIMENTAL PROGRAM}

\section{Boundary condition}


To simplify the boundary constraint condition of the surrounding structural elements to the tested substructure, the ideal fixed boundary condition is assumed in this test. The membrane action has a spatial effect when slabs are under large deformation, which means that the membranous tensile effect exists in both directions of the slabs. Because the spatial membrane effect in two directions is a very complicated mechanical behavior, only a one-directional membrane effect on the collapse resistance is studied in this test. In subsequent tests, the spatial membrane effect will be studied further. Thus, in this test, only the X-direction boundaries are set as fixed ends, and the Y-direction boundaries are set as free (see Figure 3). Therefore, only the $\mathrm{X}$-direction membrane effect exists in the slab. The boundary condition is achieved by fixing the support beams (specimen 1 in Figure 5) to the concrete base (see Figure 5). For the front side and back side of the support beam, there are two embedded steel plates, respectively, so as the concrete base. Reserved bolt holes are present in the steel plate of the concrete base. In this test, a steel cover plate with a thickness of $20 \mathrm{~mm}$ is used to connect the support beam and the concrete base via the bolted and welded connections (see Figure 5).

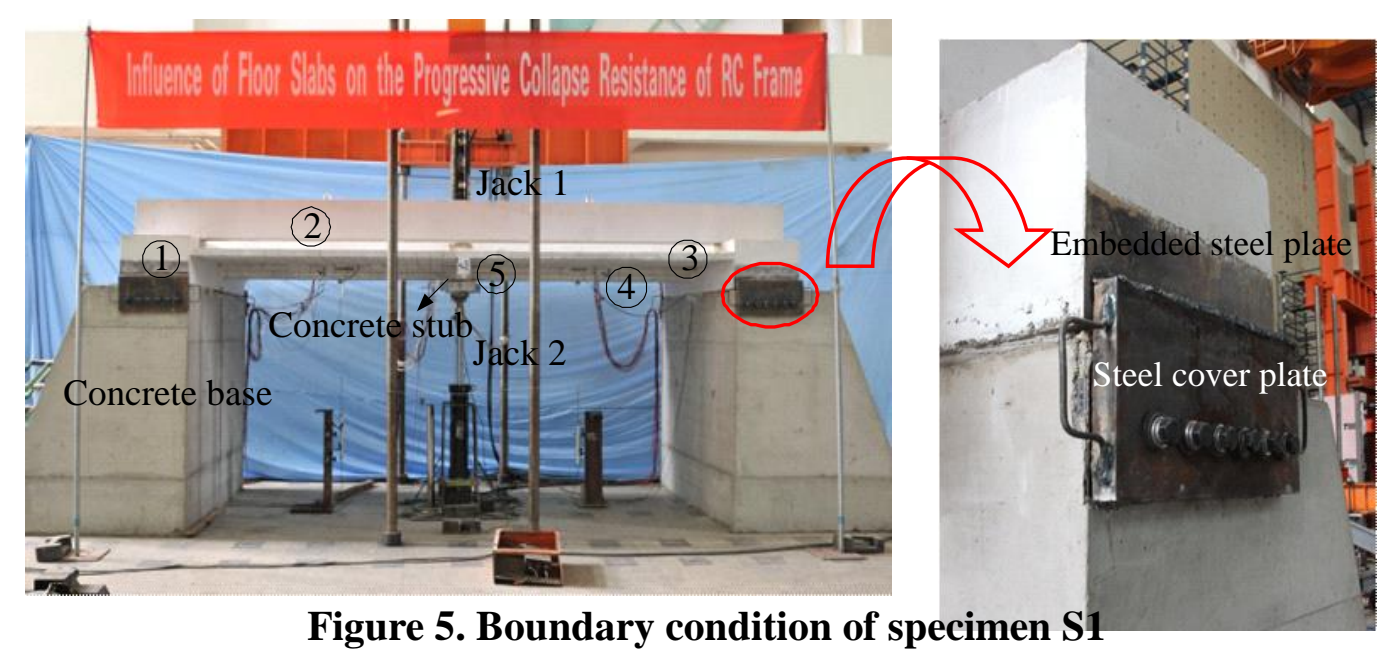

\section{Loading device}

Two hydraulic jacks were installed at the top (Jack 1) and the bottom (Jack 2) of the middle concrete stub (Figure 5). At the beginning of the experiment, Jack 1 and Jack 2 applied a pair of small balanced forces $(<10 \mathrm{kN})$ synchronously. Next, Jack 2 maintained the constant force, and at the same time, gradually increased the force of Jack 1. In this test, the displacement controlled loading was used to simulate the failure of the middle column.

\section{Measuring method}


To monitor the deformation development of the tested specimens during the whole loading process, the strain gauges were arranged on the reinforcement at critical locations, such as the bottom reinforcement at the mid-span (Section E/F), the ends (Section $A / B / C / D$ ) of the slab and the beam, and the top reinforcement at the ends (Section $\mathrm{A} / \mathrm{B} / \mathrm{C} / \mathrm{D}$ ) of the slab and the beam, as shown in Figure 2.

The linear variable differential transducers (LVDTs) were installed at four boundary locations (Figure 2) to measure the vertical displacement of the failed mid-column. Additionally, the LVDTs were also installed on the support beams (specimen 1 in Figure 5) to monitor whether the fixed boundary condition was achieved.

\section{EXPERIMENTAL RESULTS}

Figure 6 displays the load-vertical displacement curves of S1 and B1. The load-vertical displacement curve can be divided into two stages: the first stage is from the zero point to point $\mathrm{P} 3$, where the vertical load is primarily resisted by the flexural capacity of the specimen, which is called the beam mechanism stage in the study of Li et al. (2011); the second stage is the remaining curve after P3, which is called the membrane mechanism stage. In the second stage, the applied vertical load is primarily resisted by the tensile force of the specimen. Several representative points are marked on the curve. P1, P2, and P3 represent the appearance of the first flexural crack, the peak resistance of the beam mechanism stage, and the start of the membrane mechanism stage, respectively. P4, P5, P6, P7, and P8 represent the fracture of the longitudinal reinforcing steel bars in the beams and slabs.

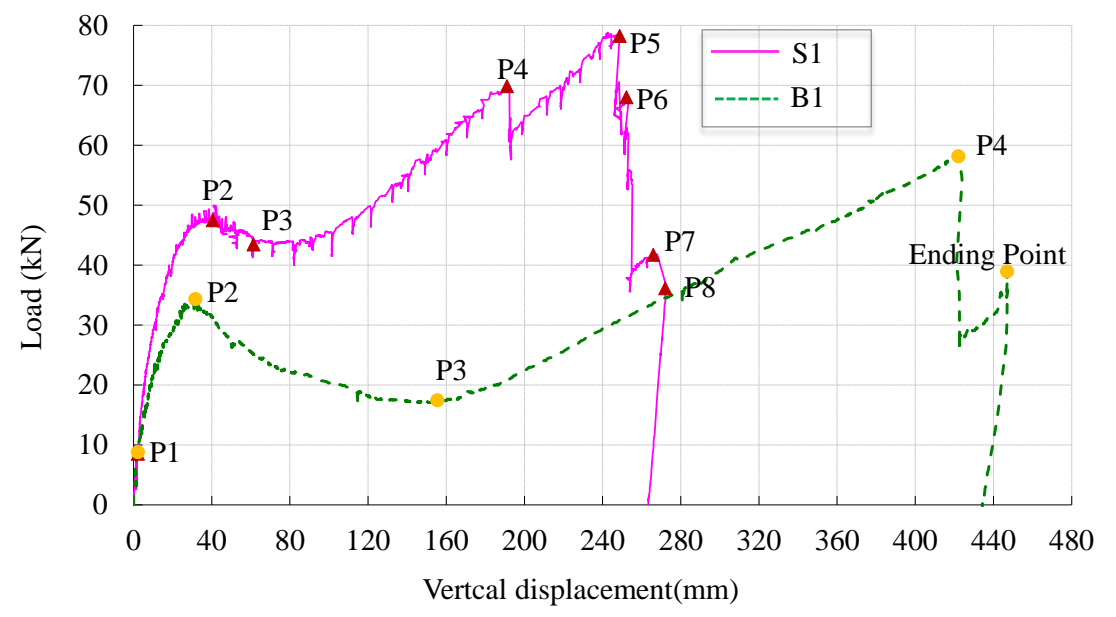

Figure 6. Load versus vertical displacement of specimens S1 and B1

For S1, the first flexural crack (P1) was observed at the bottom of Section B at a load of $9.12 \mathrm{kN}$. The corresponding displacement at P1 was $2.1 \mathrm{~mm}$. Subsequently, when the displacement reached $5.1 \mathrm{~mm}$ and $11.7 \mathrm{~mm}$, cracks at the top of Section A 
and Section B of the slab were observed. When the displacement reached $37.8 \mathrm{~mm}$, concrete crush was observed at the bottom of the beam (i.e., Section A/D) due to the action of the negative moments at these sections. Simultaneously, cracks occurred in a large area of the slab bottom at the same sections. Next, the ultimate flexural capacity was reached at a load of $49.93 \mathrm{kN}$ with a vertical displacement of $40.77 \mathrm{~mm}$. At a deflection of $62.5 \mathrm{~mm}$ and $66 \mathrm{~mm}$, concrete falling in the compression zone at Section D and Section A was discovered. The specimen reached the membrane mechanism stage (P3). At P4 (with a deflection of $191 \mathrm{~mm}$ ), two longitudinal steel bars at the bottom of the beam of Section B fractured. Simultaneously, wide cracks at the bottom of the beam and slab were observed on the rebar-fractured section. Afterwards, 5 bottom longitudinal steel bars in the left span of the slab (approximately $650 \mathrm{~mm}$ away from Section A) successively fractured at P5 (252 $\mathrm{mm})$, P6 $(266 \mathrm{~mm})$, P7 $(271 \mathrm{~mm})$, and P8 $(294 \mathrm{~mm})$, which caused a significant decrease of the load and the eventual failure of the specimen. Additionally, two steel bars simultaneously fractured at P6. At this position, a wide crack through the width of the slab and a large rotation of the slab were observed. By the end of the test, the maximum vertical displacement of the middle column reached $272.36 \mathrm{~mm}$, and the rotation of the slab was approximately $0.215 \mathrm{rad}$.

In the loading process, the failed middle column slightly rotated counterclockwise, which led to the following final crack pattern: wide cracks were primarily concentrated in the left span of the slab, and the width of the cracks in the left span was much larger than in the right span. Thus, the final fracture of the slab reinforcement rebar was concentrated in the left span.

To avoid the in-plane rotation of the failed column and the twist of the beam in the test of B1, a steel frame was installed around the ends of the Y-beam (see Figure $3 b)$.

The first flexural crack of B1 appeared at Section B and Section C at a deflection of $2.2 \mathrm{~mm}$ with a load of $8.78 \mathrm{kN}$ (P1). When the vertical displacement reached $6 \mathrm{~mm}$, cracks formed at the top of the beam at Section A. The load when the ultimate flexural resistance of B1 in the beam mechanism stage achieved was 34.34 $\mathrm{kN}$ (P2) with a deflection of $31.62 \mathrm{~mm}$. From P2 to P3, the flexural capacity of the beam gradually decreased. Afterwards, concrete crush was observed at the top of the beam at Section C $(45 \mathrm{~mm})$, at the bottom of the beam at Section D $(50 \mathrm{~mm})$ and Section A (100 mm), and at the top of the beam at Section B $(150 \mathrm{~mm})$. Finally, two bottom longitudinal steel bars at Section B fractured at P4. The vertical displacement at P4 was $421 \mathrm{~mm}$, and the corresponding load was $58.18 \mathrm{kN}$, which was the ultimate resistance in the membrane mechanism stage. Although the reinforcement steel bars in the slab could still bear the increased load through the tensile force, the experiment stopped when the stroke of Jack 1 was achieved (the Ending Point in Figure 6). The final maximum vertical displacement was $446.9 \mathrm{~mm}$, and the rotation of the beam was $0.225 \mathrm{rad}$. 
When comparing the load-vertical displacement curves of $\mathrm{S} 1$ and $\mathrm{B} 1$, the membrane mechanism stage of B1 is longer than S1 because the B1 specimen has measures to prevent the twisting of the beam, and eventually, the cracks and the steel strain developed more evenly in the two spans of the beam. On the other hand, for S1, wide cracks are primarily concentrated in the left span, and thus the steel strain in the left span developed earlier than that in the right span, which eventually caused the relatively early fracture of the reinforcement rebar in the left span. Additionally, a large area of concrete crush near the support beam was observed in S1 (Figure 7a) because the reinforcement in the slab increased the reinforcement ratio in the beam cross section, which resulted in a failure mode similar to an over-reinforced beam. On the contrary, the crush damage was not serious for B1 without slab as shown in Figure $7 \mathrm{~b}$.

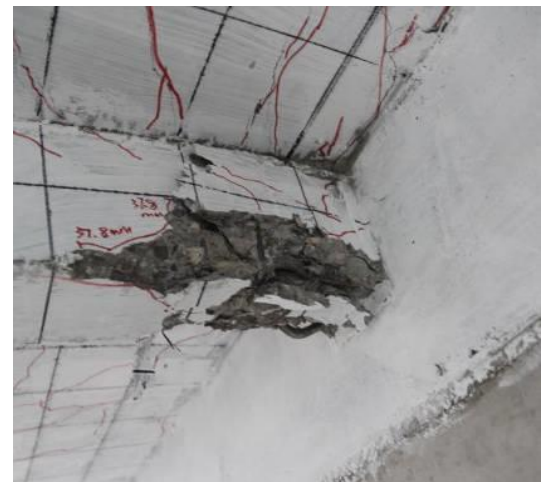

(a) Crush damage of $\mathrm{S} 1$

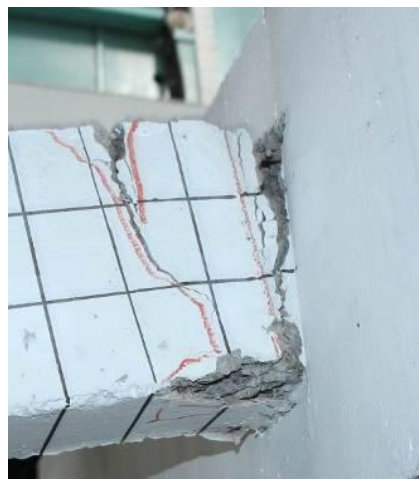

(b) Crush damage of B1

Figure 7. Crush damage of the specimens (Section D)

\section{DISCUSSION}

The peak values of the resistant capacity of S1 and B1 in two stages are demonstrated in Table 2, where Peak 1 is the resistant capacity in the beam mechanism stage, and Peak 2 is the resistant capacity in the membrane mechanism stage. D1 and D2 are the corresponding displacements to Peak 1 and Peak 2, respectively. Table 2 shows that the resistance is significantly improved when considering the contribution of the slab.

Table 2. Comparison of the peak values of the resistant capacity of S1 and B1

\begin{tabular}{c|c|c|c|c|c}
\hline & D1 (mm) & Peak 1 $(\mathrm{kN})$ & D2 $(\mathrm{mm})$ & Peak 2 (kN) \\
\hline \multicolumn{2}{c|}{ S1 } & 40.77 & 49.93 & 242.58 & 78.81 \\
\hline \multicolumn{2}{c|}{ B1 } & 31.62 & 34.34 & 421.97 & 58.18 \\
\hline Increment & S1 vs. B1 & & $45.40 \%$ & & $35.46 \%$ \\
\hline
\end{tabular}


To study the effect of the slab on the resistance of the beam-slab substructure in the progressive collapse process, the bearing capacity ratio of $\mathrm{B} 1$ and $\mathrm{S} 1$ is calculated as shown in Figure 8. The $\mathrm{X}$ axis is the vertical displacement, and the $\mathrm{Y}$ axis is the bearing capacity of B1 divided by S1 at the same displacement. The effect of the slab can be assessed by the percentage above the curve.

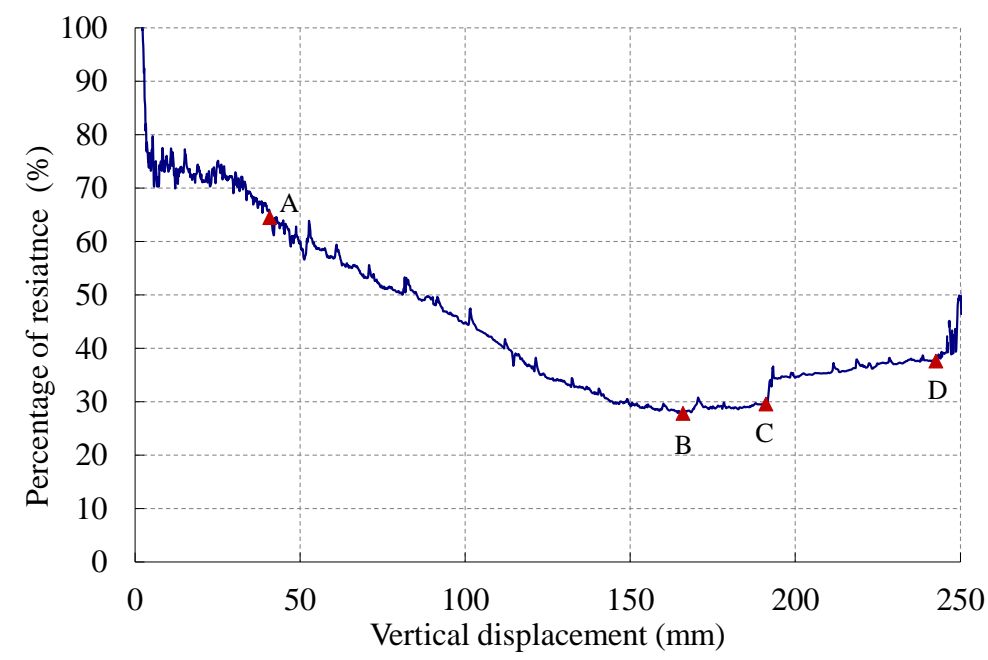

Figure 8. Resistance enhancement effect of the slab

At the beginning of the experiment, the difference between the bearing capacities of these two specimens was not very significant. As the vertical displacement increased, the effect of the slab was increasingly apparent. When Peak 1 of $\mathrm{S} 1$ (point A with a deflection of $40.77 \mathrm{~mm}$, which corresponded to point P2 in Figure 6) was reached, the resistant capacity of S1, which includes the contribution of the slab, was $55.1 \%$ higher than B1. Subsequently, the enhancement effect of the slab gradually increased with the development of the deflection. When the vertical displacement was $166 \mathrm{~mm}$ (point B), the resistance of S1 had a 259.3\% increase compared with B1. Afterwards, the enhancement effect of the slab started to decline slowly. When the first fracture of the reinforcement rebar occurred (point $\mathrm{C}$, which corresponded to point P4 in Figure 6), the resistance enhancement effect of the slab had an obvious decline. At the second peak value of the resistance (point D, which corresponded to point P5 in Figure 6), the resistance of S1 had an increase of approximately $65.7 \%$ based on B1.

\section{CONCLUSION}

For RC frame structures, the progressive collapse resistance of the structures is greatly enhanced by the slabs. For the studied scenario with the loss of the middle column, the contribution of the slab causes a $45.40 \%$ increase in the peak value of the resistant capacity of the substructure. By investigating the resistance 
enhancement effect of the slab, the slab has a significant contribution to the structural resistance during the whole collapse process, especially in the membrane mechanism stage, where the enhancement effect of the slab can be up to $259.3 \%$. Additionally, the different deformation modes of the two specimens are also observed due to the effect of the slabs. The membrane catenary mechanism of the RC beam without slab occurs earlier than that of the RC beam integrated with slab. That is due to the brittle damage at the fixed ends of the specimen with slab where the reinforcing steel bars in slabs over-reinforcing the $\mathrm{RC}$ beam.

\section{ACKNOWLEDGEMENT}

The authors are grateful for the financial support received from the National Basic Research Program of China (2012CB719703), the National Science Foundation of China (No. 51222804, 51208011) and the Research Program of Beijing Municipal Commission of Education (KM201310005025).

\section{REFERENCES}

Foster, S. J., Bailey, C. G., Burgess, I. W., and Plank, R. J. (2004). "Experimental behavior of concrete floor slabs at large displacements." Eng. Struct., 26(9), 1231-1247.

Fu, F. (2009). "Progressive collapse analysis of high-rise building with 3-D finite element modeling method.” J. Constr. Steel Res., 65(6), 1269-1278.

Gouverneur, D., Caspeele, R., and Taerwe, L. (2013). "Experimental investigation of the load-displacement behavior under catenary action in a restrained reinforced concrete slab strip." Eng. Struct., 49, 1007-1016.

Kai, Q., and Li, B. (2011). "Experimental and analytical assessment on RC interior beam-column subassemblages for progressive collapse." J. Perform. Constr. Facil., 26(5), 576-589.

Kai, Q., and Li, B. (2012a). "Dynamic performance of RC beam-column substructures under the scenario of the loss of a corner column-Experimental results.” Eng. Struct., 42, 154-167.

Kai, Q., and Li, B. (2012b). "Slab effects on response of reinforced concrete substructures after loss of corner column." ACI Struct. J., 109(6), 845-856.

Kwasniewski, L. (2010). "Nonlinear dynamic simulations of progressive collapse for a multistory building." Eng. Struct., 32(5), 1223-1235.

Li, Y., Lu, X. Z., Guan, H. and Ye, L. P. (2011). "An improved tie force method for progressive collapse resistance design of reinforced concrete frame structures." Eng. Struct., 33(10), 2931-2942.

Ministry of Housing and Urban-Rural Development of the People's Republic of China (MOHURD). (2010a). Code for design of concrete structures. (GB50010-2010), Beijing. 
Ministry of Housing and Urban-Rural Development of the People's Republic of China (MOHURD). (2010b). Code for seismic design of buildings. (GB50011-2010), Beijing.

Sadek, F., Main, J. A., Lew, H. S., and Bao, Y. (2011). "Testing and analysis of steel and concrete beam-column assemblies under a column removal scenario." $J$. Struct. Eng., 137(9), 881-892.

Sagiroglu, S. and Sasani, M. (2013). "Progressive collapse resisting mechanisms of reinforced concrete structures and effects of initial damage locations." J. Struct. Eng. 10.1061/ (ASCE) ST.1943-541X.0000854.

Su, Y., Tian, Y., and Song, X. (2009). "Progressive collapse resistance of axially-restrained frame beams." ACI Struct. J., 106(5), 600-607.

Yi, W. J., He, Q. F., Xiao, Y., and Kunnath, S. K. (2008). "Experimental study on progressive collapse-resistant behavior of reinforced concrete frame structures." ACI Struct. J., 105(4), 433-439. 